\title{
La constitución de la violencia de género como problema público y los frames sobre aborto: revisión crítica de antecedentes y propuesta de análisis
}

\author{
Paola Ingrassia \\ CONICET. Universidad Nacional de San Juan. \\ paoingrassia2@gmail.com \\ Fecha de finalización: 29 de agosto de 2020 . \\ Recibido: 30 de agosto de 2020 \\ Aceptado: 9 de noviembre de 2020 . \\ DOI: https://doi.org/10.26422/aucom.2020.0902.ing
}

\section{Resumen}

Un problema público representa una mirada particular de una situación en un momento dado. Se trata de un proceso selectivo entre una multiplicidad de realidades potenciales que requiere de una definición colectiva que lo legitime en una arena competitiva, en la que se disputa el sentido de todas las problemáticas sociales. Allí, los medios de comunicación son actores clave, puesto que en las noticias periodísticas se definen situaciones problemáticas y se atribuyen responsabilidades.

En ese sentido, el objetivo general del artículo es analizar la constitución de la violencia de género como problema público. En lo específico, se apunta a evaluar los antecedentes que hicieron posible la definición del carácter problemático de la violencia contra las mujeres, comprender los eventos críticos (Staggenborg, 1993) que legitimaron al activismo feminista en redes sociales y analizar los contenidos mediáticos sobre el aborto. El trabajo triangula las perspectivas de los problemas públicos (Blumer, 1971; Gusfield, 1981, 2014; Pereyra, 2010) con los lineamientos de los movimientos sociales (Gamson, 1992; Meyer y Staggenborg, 1996; 2015; Snow y Benford, 1988, 1992; Staggenborg, 2001), de los estudios de género (Ciriza, 2007; De Beauvoir, 1949; De Miguel Álvarez, 2003; Wollstonecraft, 1998) y del framing (D’Angelo, 2012; Entman, 1993).

Entre los resultados se destacan las estrategias y recursos para la lucha política feminista en el contexto de un orden patriarcal (Amorós, 1991; Lagarde, 1996; Millett, 1975). Además, se evidencian las prácticas periodísticas que apuntan a reforzar la situación de injusticia que padecen las mujeres y la forma en la que se consolidan responsabilidades individuales en lugar de políticas o sociales.

Palabras clave: violencia de género, problemas públicos, movimientos sociales, patriarcado, frames noticiosos, aborto. 


\title{
Gender violence as a public issue and the framing of abortion: a look
} at the antecedents of the current situation and a proposal for analysis

\begin{abstract} problematic situations and attribute responsibilities. Entman, 1993). in individual - rather than political or social - terms.

\section{A constituição da violência de gênero como problema público e os frames do aborto: revisão crítica dos antecedentes e proposta de análise}

A public issue is a particular view of a situation at a certain point in time. It involves a selective process, via which the issue is plucked from a multiplicity of potential realities and goes through a collective definition that legitimizes it upon a competitive arena, where the meaning of all social issues is in dispute. Communication media are crucial in this process, as news outlets define

In this sense, the goal of our paper is to analyze how gender violence has been established as a public issue. Specifically, it aims to evaluate the antecedents that made it possible to define the problematic character of violence against women, understand the critical events (Staggenborg, 1993) that legitimized feminist activism on social media, and analyze media contents regarding abortion. Our work merges perspectives on public issues (Blumer, 1971; Gusfield, 1981, 2014; Pereyra, 2010) with concepts from social movements (Gamson, 1992; Meyer and Staggenborg, 1996; 2015; Snow and Benford, 1988, 1992; Staggenborg, 2001), gender studies (Ciriza, 2007; De Beauvoir, 1949; De Miguel Álvarez, 2003; Wollstonecraft, 1998) and framing (D’Angelo, 2012;

Among our results, we highlight the strategies and resources employed by feminist political activism in a patriarchal context (Amorós, 1991; Lagarde, 1996; Millett, 1975). Moreover, we reveal journalistic practices that seek to reinforce injustice against women and attribute responsibility

Keywords: gender violence, public issues, social movements, patriarchy, news framing, abortion.

\section{Resumo}

Um problema público representa uma visão particular de uma situação em um determinado momento. Trata-se de um processo seletivo entre uma multiplicidade de realidades potenciais que requer de uma definição coletiva que o legitime em uma arena competitiva na qual se disputa o sentido de todas as problemáticas sociais. Ali, os meios de comunicação são atores chave já que nas notícias jornalísticas se definem situações problemáticas e se atribuem responsabilidades.

Nesse sentido, o objetivo geral desta investigação é analisar a constituição da violência de gênero como problema público. Especificamente, o objetivo é avaliar os antecedentes que possibilitaram a definição da problemática da violência contra a mulher, compreender os eventos críticos (Staggenborg, 1993) que legitimaram o ativismo feminista nas redes sociais e analisar os conteúdos mediáticos sobre $\mathrm{o}$ aborto. $\mathrm{O}$ trabalho triangula as perspectivas dos problemas públicos (Blumer, 1971; Gusfield, 1981, 2014; Pereyra, 2010), com as diretrizes dos movimentos sociais (Gamson, 1992; Meyer y Staggenborg, 1996; 2015; Snow y Benford, 1988, 1992; Staggenborg, 2001), estudos de gênero (Ciriza, 2007; De Miguel Álvarez, 2003; De Beauvoir, 1949; Wollstonecraft, 1998) e enquadramento (D’Angelo, 2012; Entman, 1993).

Entre os resultados destacam-se as estratégias e recursos para a luta política feminista no contexto de uma ordem patriarcal (Amorós, 1991; Lagarde, 1996; Millett, 1975). Além disso, se evidenciam as práticas jornalísticas que apontam a reforçar a situação de injustiça que padecem as mulheres e a forma em que se consolidam responsabilidades individuais no lugar de políticas ou sociais. 
Palavras chave: violência de gênero, problemas públicos, movimentos sociais, patriarquia, patriarcado, news frames, aborto.

\section{Introducción}

Durante los primeros siete meses de 2020, se perpetraron 178 femicidios en Argentina. Es decir, la violencia machista, entendida como el tipo de violencia que los varones ejercen contra las mujeres en el marco de una relación desigual de poder (Rosales, 2018), terminó con la vida de una mujer cada 29 horas durante esos meses. Las cifras surgen del análisis de medios gráficos y digitales de todo el país que realizó el Observatorio de las violencias de género Ahora que sí nos ven (2020) en el período que va del 1 de enero al 31 de julio de 2020.

En un sentido similar, el Observatorio MuMaLá "Mujeres, Disidencias, Derechos" afirma que en el mismo período fueron 160 los femicidios y que otras 26 muertes violentas de mujeres están aún en proceso de investigación (Mujeres de la Matria Latinoamericana [Mumalá], 2020).

No existen datos oficiales respecto a la estadística alcanzada, puesto que los registros que elabora la Oficina de la Mujer -dependiente de la Corte Suprema de Justiciason anuales (se publican desde 2015 en el mes de junio, en coincidencia con las marchas denominadas \#Ni Una Menos). En el último Informe de Femicidios presentado, la cantidad de "víctimas letales de la violencia de género en Argentina durante 2019 asciende a 268" (Registro Nacional de Femicidios de la Justicia Argentina, 2019, p. 2).

Las violaciones y los femicidios como máximas expresiones de la violencia machista aumentan año a año a nivel nacional e internacional y son producto de un entramado social, económico, político y cultural que se sustenta en la desigualdad. Erradicar este problema social es un reto pendiente, no solo para nuestro país, sino para América Latina en general. El 8 de marzo de 2020, en su declaración por el Día Internacional de la Mujer, la directora ejecutiva de ONU Mujeres, Phumzile Mlambo-Ngcuka, alertó sobre la situación de inequidad y violencia que viven las mujeres y niñas de todo el mundo y reclamó la colaboración internacional para derribar las barreras contra la igualdad de género (ONU Mujeres, 8 de marzo de 2020). El pedido se reforzó en los meses siguientes frente al incremento de los reportes de violencia intrafamiliar en el marco de la pandemia originada por el virus COVID-19. ${ }^{1}$

Ahora bien, los problemas sociales no existen en la naturaleza como algo dado de antemano, sino que representan un proceso selectivo entre una multiplicidad de

El 30 de enero de 2019, la Organización Mundial de la Salud (ONU) declaró que el brote de COVID-19 constituía una emergencia de salud pública de preocupación internacional (Organización Panamericana de la Salud, 2020). En Argentina, el presidente Alberto Fernández decretó el aislamiento social, preventivo y obligatorio a partir de las cero horas del 20 de marzo de ese año (Ministerio de Salud, 2020). La medida se extiende hasta la actualidad, con excepciones en algunas provincias. 
Paola Ingrassia

La constitución de la violencia de género como problema público y los frames sobre aborto: revisión crítica de antecedentes y propuesta de análisis

realidades potenciales. En consecuencia, para que sean reconocidos como tales, precisan de una definición de la realidad específica. "Los problemas humanos no se presentan de pronto, completamente desplegados y anunciados, en la conciencia de los observadores. El solo hecho de reconocer que una situación es dolorosa requiere un sistema que permita categorizar y definir los acontecimientos" (Gusfield, 2014, p. 63). De esa manera, solo algunos de los problemas sociales se vuelven temas de conflicto en la arena de la atención pública. Por ello, para analizar un problema público, es necesario comprender la manera en la que este alcanzó ese estatus, que es, precisamente, lo que lo distingue de un problema privado o personal. En efecto, los problemas tienen historia, puesto que no siempre fueron considerados como tales y puede que sean reconocidos de una manera distinta en el futuro (Gusfield, 2014). Así, su existencia requiere de un proceso de definición colectiva que lo legitime (Blumer, 1971). En esa línea, la constitución de un problema público comprende: 1) una definición moral: la situación se evalúa como negativa porque causa algún daño a alguien; 2) un carácter extendido: esa situación adquiere un estatus social porque afecta a un número considerable de personas; 3 ) una dosis de optimismo: la situación problemática se evalúa como susceptible de ser modificada por la acción humana; y 4) una necesidad de hacer algo al respecto para cambiar esa situación (Pereyra, 2010). Este último punto es lo que Gusfield (1981) destaca como el carácter principal de un problema público, ya que la consideración de que alguien debe hacer algo sobre un asunto justifica el reclamo de la "atención pública".

Desde este enfoque, si los problemas no logran acceder a ciertos ámbitos como los medios de comunicación, las instancias de gobierno, las instituciones sociales, la Iglesia o la escuela, suelen ser desestimados. En cambio, si logran la legitimación social por medio de una de esas arenas competitivas (Hilgartner y Bosk, 1988) en las que se disputa el sentido de todas las problemáticas sociales por imponer una definición de situación (Thomas, 1923), se convierten en materia de discusión o de controversia pública. En efecto, se trata de un proceso en el que se organizan ciertas categorías para definir la realidad con el fin de reclamar la atención pública sobre un asunto en particular (Gusfield, 1981). En otras palabras, un problema público representa una selección específica de una realidad por sobre otras y una organización particular de los personajes, las causas y las soluciones que caracterizan a ese problema. Por ello, es preciso considerar que la comprensión de cualquier hecho supone un modo de interpretación establecido a partir de tipificaciones y categorías (Pereyra, 2010). Por ejemplo, una muerte puede ser tipificada, legalmente o a través del sentido común, de diversas maneras, sea como asesinato, tragedia o accidente, entre otras.

En ese sentido, el objetivo general de este artículo es analizar la constitución de la violencia de género como problema público. En lo específico, se apunta a evaluar los 
antecedentes que hicieron posible la definición del carácter problemático de la violencia contra las mujeres, comprender los eventos críticos (Staggenborg, 1993) que legitimaron al activismo feminista en redes sociales y analizar los contenidos mediáticos sobre el aborto.

\section{Movimientos sociales, contramovimientos y marcos de significación para la acción colectiva}

Los movimientos feministas que lograron redefinir la situación social de las mujeres a lo largo de la historia y deslegitimar la violencia de género como una práctica social esperada son movimientos sociales en el sentido propuesto por Meyer y Staggenborg (1996). Con base en la tradición económica (Tarrow, 1994), el autor y la autora definen a los movimientos sociales como un medio de reclamos urgentes (Tilly, 1984) cuyas características principales son: la identidad colectiva de los retadores, la combinación de tácticas institucionales y no institucionales y la interacción dinámica y sostenida con la política y la cultura convencional. En tanto, el contramovimiento se caracteriza por realizar afirmaciones contrarias y en forma simultánea a las del movimiento original. En sus propios términos, la noción de "movimiento social" implica "desafíos colectivos de personas con propósitos comunes y solidaridad en una interacción sostenida con las élites, los opositores y las autoridades" (Meyer y Staggenborg, 1996, p. 1631).²

Así definidos, los movimientos utilizan mecanismos específicos para orientar la acción colectiva. Para Snow y Benford (1988), que retoman el concepto goffmaniano de "marco" (1974), se trata de esquemas interpretativos que simplifican y condensan la realidad a través de la selección y codificación de objetos, situaciones, eventos, experiencias $\mathrm{y}$ secuencias de acciones relacionadas con el presente o con el pasado del movimiento social (Snow y Benford, 1992). De esa manera, las organizaciones producen sentidos para disputar imaginarios a partir de "marcos de significación para la acción colectiva" que se delinean a partir de tres elementos: el diagnóstico, el pronóstico y la motivación. El marco de diagnóstico define al problema, junto con sus causas y sus responsables. El marco de pronóstico propone una solución para ese problema social, a la vez que identifica las estrategias, tácticas y objetivos. Es decir, señala qué se debe hacer frente al diagnóstico. Por último, el marco motivacional enfatiza los motivos para que los actores se comprometan a participar en la acción colectiva. Este es el marco más importante por ser el que impulsa la acción colectiva y por ofrecer las razones para identificarse con los objetivos y valores del movimiento. Representa el énfasis o foco de atención de cada esquema interpretativo y las estrategias a través de las cuales se construye un relato para conseguir un mayor impacto y lograr la adhesión y movilización del público.

Traducción propia. 
Paola Ingrassia

La constitución de la violencia de género como problema público y los frames sobre aborto: revisión crítica de antecedentes y propuesta de análisis

En esa línea, Gamson (1992) se focaliza en el proceso de creación de los marcos en el seno de los movimientos y, siguiendo a Snow y Benford (1988), define a los "marcos de la acción colectiva" como un conjunto de creencias y significados orientados a la acción, que inspiran y legitiman las actividades y campañas del movimiento social. Estos ofrecen formas de comprender la necesidad y la conveniencia de adoptar una acción específica. Desde su mirada, son "marcos de injusticia" (Gamson, 1992, p. 7) que entran en una arena que ha sido ocupada de antemano por un marco legitimado con el cual comienzan una competencia. Así, el marco hegemónico es asumido como natural por todos los actores presentes en la arena, incluso por los disidentes, que afrontan el desafío de superar aquella definición de la situación. En ese sentido, la conciencia política que sustenta la participación en una acción colectiva se delinea a partir de tres dimensiones: injusticia, agencia e identidad. El componente de injusticia implica una indignación moral frente a una situación que se interpreta como intencional y dañina. El componente de agencia o eficacia colectiva pondera la posibilidad de cambiar las condiciones a través de la acción colectiva. Por medio de esta dimensión, las personas llegan a percibirse a sí mismas como agentes de su propia historia. Por último, el componente de identidad prevé la identificación en una arena de dos actores: un "nosotros", el agente colectivo, frente a un "ellos", el adversario que posee intereses o valores diferentes a los definidos como propios por el colectivo.

En un sentido similar, Staggenborg (2001) afirma que los movimientos sociales operan en un campo político específico y que, a la vez, son influenciados por las características de ese campo. Al analizar la compleja relación que existe entre las acciones culturales y las acciones políticas entre las activistas del movimiento de mujeres de Bloomington, Indiana (1960-1990), la autora concluye que las actividades de los movimientos se delinean en torno al clima político del momento y a la precepción respecto a las amenazas y oportunidades políticas. Así, en los períodos en los que se advierte una oportunidad o una amenaza para un fin específico, las activistas se animan tanto a proyectos culturales como a proyectos políticos. En cambio, durante los períodos lentos, es decir, cuando existen escasas oportunidades de obtener ganancias políticas, los proyectos culturales resultan particularmente atractivos y se reduce la atención a las actividades políticas.

De cualquier forma, las actividades culturales son clave en todos los momentos porque ayudan a mantener la identidad colectiva feminista y proveen redes de acción a los grupos políticos. En paralelo, la acción política se define a partir de tres factores que motivan a participar y/o evitan el aislamiento y la decadencia del movimiento. El primero es el que impulsa a la acción e incluye tanto a los eventos externos como a las acciones del contramovimiento. Por ejemplo, una violación muy publicitada, un ataque a homosexuales o las manifestaciones para la apertura de la clínica de abortos 
motivan a participar en las actividades del movimiento. El segundo es el que revitaliza a la comunidad local y permite generar nuevas acciones colectivas, como la incorporación de otras activistas que renueven la energía de las participantes y las conexiones con organizaciones nacionales que ayuden a reformular las estrategias de lucha. El tercero es el que permite extender los límites del movimiento a partir de la vinculación institucional, que es la que posibilita la generación de acciones colectivas expansivas.

En una investigación posterior, Meyer y Staggenborg (2015) hacen foco en las estrategias de lucha de los movimientos sociales y de los contramovimientos. Para su estudio, utilizan los eventos publicados por The New York Times entre 1959 y 1996 sobre el debate por el derecho al aborto, con el fin de analizar las estrategias implementadas en la disputa que comenzó en 1960 en Estados Unidos. En línea con Jenkins (1981), Meyer y Staggenborg (2015) definen a la "estrategia" como un plan de acción que organiza la movilización de recursos y delimita la serie de acciones colectivas que son necesarias para lograr los cambios sociales deseados. "En la práctica, la estrategia implica procesos de toma de decisiones en interacción con movimientos opuestos, autoridades y otros actores en el campo multi-organizacional del movimiento (Curtis y Zurcher, 1973)" (Meyer y Staggenborg, 2015, p. 212). ${ }^{3}$ Así comprendida, la estrategia se diseña a partir de tres elementos clave: las arenas de acción, las tácticas de promoción y las demandas. Con "arenas" se refieren al campo de acción que seleccionan los actores (entendidos como funcionarios gubernamentales, grupos religiosos, partidos políticos y otras partes interesadas en el problema) del movimiento para la acción colectiva. Se trata de la elección de un escenario sobre el que se definen objetivos y niveles de acción. Por ejemplo, los movimientos que actúan en las arenas legislativas pueden apuntar al Congreso o a los legisladores provinciales. Así, los movimientos cambian las arenas, los niveles o los objetivos con base en las acciones de los oponentes y en la receptividad que encuentren en los actores presentes en la arena. En tanto, las tácticas se delinean a partir de la elección previa de la arena y/o del objetivo principal. Se trata de aquellos medios específicos para implementar la estrategia y de las formas que adoptará la acción colectiva. Los autores las clasifican en dos grupos: acciones institucionales $\mathrm{y}$ acciones directas. Los procedimientos institucionales comprenden aquellas acciones emprendidas a través de instituciones políticas previamente legitimadas. En cambio, las acciones directas son las que pasan por alto los canales de acción establecidos, como manifestaciones, boicots y acciones basadas en acosar o defender a ciertas personas, entre otras. Además de seleccionar lugares o escenarios y formas de acción, los movimientos toman decisiones estratégicas sobre las demandas a realizar, junto con los encuadres, los contenidos y las formas de presentar el problema. Así, los movimientos se centran en cuestiones particulares en diferentes momentos y utilizan distintos

Traducción propia. 
Paola Ingrassia

La constitución de la violencia de género como problema público y los frames sobre aborto: revisión crítica de antecedentes y propuesta de análisis

marcos de acción colectiva para cada demanda concreta (Snow y Benford, 1992). Los tres elementos son susceptibles de modificarse a partir de las interacciones, los eventos críticos (Staggenborg, 1991, 1993) o los resultados obtenidos. A la vez, las demandas del contramovimiento, junto con sus marcos de acción, dependen del contexto cultural y de la interacción con el Estado y con el movimiento opuesto.

\title{
El proceso de definición feminista de la violencia de género
}

\begin{abstract}
Es tener conciencia de género, eso que a veces parece una condena porque te obliga a estar en una batalla continua pero consigue que entiendas por qué ocurren las cosas y te da fuerza para vivir cada día (Varela, 2008, p. 14).
\end{abstract}

En el marco de los conceptos precedentes, es posible interpretar las acciones de los movimientos feministas que hicieron posible la constitución de la violencia de género como un problema público y evaluar los principales antecedentes que sentaron las bases para la definición de su carácter problemático.

El proceso de definición para la toma de conciencia actual se inició en el Siglo de la Razón, a pesar de que la Ilustración no fue en sí misma feminista (Valcárcel, 2001). Durante el siglo XVIII, los revolucionarios e ilustrados franceses defendieron los ideales de "igualdad, libertad y fraternidad" para cuestionar políticamente los privilegios de cuna, aunque excluyeron a las mujeres de la ciudadanía y de todo lo que ella implicaba. Así surgió el feminismo. Las principales referentes de la época comenzaron una lucha que signó el destino de las mujeres a lo largo de la historia a partir de un reclamo concreto: igualdad entre hombres y mujeres. Desde allí, criticaron la supremacía masculina, denunciaron los mecanismos sociales y culturales determinantes en la construcción de la subordinación femenina y propusieron estrategias para conseguir la emancipación de las mujeres.

En este marco de toma de conciencia feminista, se destacan en el contexto europeo y americano los nombres de Olimpia de Gouges y Mary Wollstonecraft, las primeras revolucionarias en proclamar los derechos de las mujeres. En 1791, Olimpia de Gouges publicó la Declaración de los Derechos de la Mujer y de la Ciudadana, una de las principales obras en defensa del derecho al voto femenino, en respuesta a la Declaración de los Derechos del Hombre y del Ciudadano (1789), que afirmaba la distinción entre dos categorías de ciudadanos: los activos -varones mayores de veinticinco años, independientes y con propiedades- y los pasivos -hombres sin propiedades y todo el colectivo de mujeres- (Beltrán, Maquieira, Álvarez y Sánchez, 2008). Su objetivo fue repudiar los derechos políticos negados a las mujeres en un escenario en el que los revolucionarios defendían los principios universales de igualdad y libertad, pero, al mismo tiempo, excluían a las mujeres de tales principios. 
En 1792, la inglesa Mary Wollstonecraft escribió la "Vindicación de los derechos de la mujer" e instaló la idea de género para señalar que lo considerado como natural en las mujeres era consecuencia de la voluntad de los hombres y del aprendizaje social.

Y si se concede que la mujer no fue creada simplemente para satisfacer el apetito del hombre o para ser la sirvienta más elevada, que le proporciona sus comidas y atiende su ropa, se seguiría que el primer cuidado de las madres o padres que se ocupan realmente de la educación de las mujeres debería ser, si no fortalecer el cuerpo, al menos no destruir su constitución por nociones erróneas sobre la belleza y la excelencia femenina (Wollstonecraft, 1998, p. 182).

Otro antecedente clave para la actual definición social de la "violencia de género" se dio en el siglo XIX (De Miguel Álvarez, 2003) de la mano de los feminismos sufragistas y socialistas. Sus esfuerzos se centraron en desarticular la ideología de la naturaleza diferente y complementaria de los sexos y en la lucha por los derechos básicos. También visibilizaron las condiciones de coacción y violencia que rodeaban a la condición femenina. Para las feministas de la época, conseguir el voto y la entrada en las instituciones de alta educación eran sus principales objetivos. Esa lucha por la reivindicación del derecho al sufragio explica la denominación de "sufragistas" (De Miguel, 2008), desde la cual las mujeres continuaron con la lucha inaugurada en el siglo XVIII (Varela, 2008). Las sufragistas confiaban en que, una vez conseguido el derecho al voto, sería posible alcanzar la igualdad en sentido amplio (Varela, 2008).

En paralelo, las bases del movimiento socialista femenino se consolidaron en el siglo XIX de la mano de Clara Zetkin, quien sentó los cimientos para el desarrollo del movimiento, y de Alejandra Kollontai con su obra célebre Memorias (1979) (De Miguel Álvarez, 1995). Para Zetkin, los problemas de la proletaria no se debían a sus maridos, sino que tenían que ver con el sistema capitalista y con la explotación económica. En la misma línea, Kollontai subrayaba la necesidad del surgimiento de "una mujer nueva", con independencia económica, psicológica y sentimental (Beltrán, Maquieira, Álvarez y Sánchez, 2008). La mujer nueva debía alcanzar nuevos fines: un ideal social, el estudio de la ciencia, una vocación o el trabajo creador (De Miguel Álvarez, 1994) y apartarse de la vinculación tradicional con el mundo de los sentimientos, cuyo máximo objetivo era la consecución del amor. Las socialistas apoyaban tácticamente las demandas de las sufragistas, pero, en paralelo, las consideraban enemigas de clase por advertir que no contemplaban la situación de las proletarias (De Miguel Álvarez, 1995). Ese fue el principal motivo de la desunión entre ambos movimientos.

Luego de la Segunda Guerra Mundial, finalmente se consolidó el sufragio universal y los derechos educativos para toda la población. En consecuencia, durante el período de entreguerras comenzó la decadencia del feminismo (Varela, 2008). 
Paola Ingrassia

La constitución de la violencia de género como problema público y los frames sobre aborto: revisión crítica de antecedentes y propuesta de análisis

En 1949, Simone de Beauvoir publicó El segundo sexo y sentó las bases para una nueva etapa de los movimientos feministas. Desde su enfoque, tanto el género como los roles son conductas asignadas social e históricamente a mujeres y hombres que poseen un carácter cultural de corte machista. En otras palabras, los creadores de la cultura son los hombres y es, precisamente, en un mundo masculino signado por su poder donde la mujer siempre ha sido considerada "la otra" sin que eso implique una reciprocidad."La mujer se determina y diferencia con relación al hombre, y no éste con relación a ella; ésta es lo in-esencial frente a lo esencial. Él es el Sujeto, él es lo Absoluto: ella es el Otro" (De Beauvoir, 1949, p. 3).

A fines de la década del 60, estas ideas se nutrieron de una nueva impronta con el surgimiento del feminismo radical. El movimiento, que nació de la New York Radical Feminist (1969) y del New York Radical Women (1967), instaló al género como categoría de estudio en la investigación sobre las mujeres y con ello puso en escena las inequidades que padecía este colectivo en distintas esferas. Con el término "patriarcado" utilizado en sentido crítico, las radicales denunciaron al sistema político de opresión común de las mujeres en todas las dimensiones (sexual, familiar, económica, cultural y política) y clasificaron al orden sociomoral que sostenía y perpetuaba la jerarquía masculina (Valcárcel, 2001). En ese contexto, Kate Millett (1975) define al patriarcado como una ideología dominante y afirma que "la sociedad patriarcal ejercería un control insuficiente, e incluso ineficaz, de no contar con el apoyo de la fuerza, que no sólo constituye una medida de emergencia, sino también un instrumento de intimidación constante" (p. 58). Además, la escritora denuncia que existe una invisibilidad de la violencia contra las mujeres y que predomina la asociación de esta problemática con hechos individuales. El marco de interpretación propuesto por Millet se consolida entre las feministas de la época para definir a la violencia contra las mujeres como un problema de índole estructural que afecta a todo el colectivo femenino.

En la misma línea, Susan Brownmiller (1981) explica la manera en la que el miedo a la violación condiciona el comportamiento cotidiano de todas las mujeres y expone que, en ese sentido, todas son víctimas de la violación. Su caso representa un hito en la autoconciencia del giro interpretativo que protagonizó el feminismo. Es "el paso de la interpretación patriarcal a la feminista. La violación forma parte del proceso de intimidación masculina del que son víctimas todas las mujeres, no sólo las que han sido violadas" (De Miguel Álvarez, 2005, p. 240).

Desde estas bases, las feministas radicales popularizaron la noción de que "lo personal es político" (Varela, 2008) y denunciaron los beneficios económicos, sexuales y psicológicos que percibían los varones bajo el amparo del sistema patriarcal (Lagarde, 2000) productor y reproductor de la opresión de la mujer (Ulloa Ziáurriz, 2011). 


\begin{abstract}
El sistema patriarcal presenta formas de opresión y legitimación propias y distintas, no sólo relacionadas con la desigualdad en la esfera de lo público, sino muy fundamentalmente con las prácticas que tiene lugar en la esfera de lo privado. Las feministas radicales ampliaron el concepto de lo político al extenderlo a todo tipo de relaciones estructuradas por el poder, como las que se dan entre varones y mujeres (De Miguel Álvarez, 2005, p. 238).
\end{abstract}

En esa definición de la situación, el término "opresión" tuvo un valor central a nivel simbólico, puesto que implicó la rebelión de un gran grupo social. Como explica Portolés (2005), en los 70 comienza a utilizarse esa expresión junto al concepto de "patriarcado" para denunciar una estructura de poder en un doble sentido: "Tiene un sentido analítico (designa a un sistema y no a un conjunto de coincidencias) y sintético (se trata de un sistema político)" (p. 54).

Desde profundas reflexiones filosóficas, Amorós (1991) conceptualiza al patriarcado como un orden simbólico y afirma que la opresión de la mujer surge con el inicio de las estructuras del parentesco, "que redefine culturalmente los papeles del macho y de la hembra humanos" (p. 63) en la sociedad patriarcal. En línea con Rosolato (1974), la filósofa española enfatiza que "la genealogía masculina es una institución específicamente cultural que se constituye como un orden simbólico estructurado en torno al Nombre del Padre, que funciona como pivote del sistema" (p. 67). Por tanto, la familia se estructura en torno al apellido del padre, ya que es "un modo de remitirse a él" (p. 68). ${ }^{4}$ Es en la constitución del apellido donde encuentra su origen el sistema patrilineal.

Parecería como si la inserción del macho de la especie humana en el proceso de la reproducción de su especie no tuviera otra alternativa que la de configurarse como control en el nivel del sistema de las relaciones de poder [...] (Rosolato, 1974, p. 68).

Así, Amorós (1991) define a la razón patriarcal como razón genealógica y legitimadora que impone un sentido por el cual se define a sí misma como fundadora del verdadero sentido.

En este marco de ideas, patriarcado es un orden sociocultural de poder basado en patrones de dominación, control o subordinación (Ulloa Ziáurriz, 2011); es el sistema social imperante que establece condiciones estructurales para definir a las mujeres y favorecer, invisibilizar o justificar la violencia contra ese colectivo (Femenías, 2011).

En palabras de Rich (1986), el patriarcado reside en el poder de los padres: un sistema familiar y social, ideológico y político en el que los hombres definen el papel que las mujeres deben interpretar y en el que están en toda circunstancia sometidas al varón. Por tanto, la cultura patriarcal cimienta el poder masculino en la represión de la sexualidad femenina y el sometimiento de las mujeres (Belli, 2017).

Cursiva en el original 
Paola Ingrassia

La constitución de la violencia de género como problema público y los frames sobre aborto: revisión crítica de antecedentes y propuesta de análisis

Sin embargo, aquella idea de una opresión común fue altamente discutida por los movimientos feministas de América Latina de los 70 por considerar que la propuesta política europea no contemplaba las diferencias de raza, clase, etnia, sexo y género. Por eso, las feministas latinoamericanas enfatizaron la necesidad de analizar las desigualdades de las mujeres en contexto (Espinosa Miñoso, 2016). Así, se consolidó el feminismo decolonial, centrado en el cuestionamiento al sujeto único, al eurocentrismo, al occidentalismo, a la colonialidad del poder, al tiempo que reconoce propuestas como la hibridación, la polisemia, el pensamiento otro, subalterno y fronterizo (Curiel, 2009). Como apunta Ciriza (2013), las feministas latinoamericanas fueron parte de un "proceso de insurgencia" en el que las mujeres adquirieron visibilidad en la esfera pública como movimiento social y político orientado a transformar la dominación patriarcal imperante (Rodríguez Agüero, 2015).

En esa línea, los principales objetivos de las activistas fueron constituir a la violencia contra las mujeres como un problema de índole público, alejado de las lógicas que la configuraban como un tema privado y hasta esperable dentro del ámbito familiar (Castro y Riquer, 2003; Di Marco, 2010; Sagot, 2008) y reclamar por el derecho a decidir sobre su propio cuerpo (Lamas, 2008). Esta lucha se encuadró con los reclamos de las mujeres italianas, francesas, norteamericanas, inglesas y alemanas.

\begin{abstract}
La batalla setentista por el derecho al aborto se produjo en un clima social y político que reunía una serie de factores: la expansión de libertades y derechos, incluida una revolución cultural que transformó las relaciones interpersonales (aumento de los divorcios, liberalización de las costumbres), el uso de las píldoras como innovación tecnológica, que se leía en sintonía con la batalla feminista por la libertad y la autonomía de las mujeres, pues se suponía que los anticonceptivos orales harían de las mujeres las dueñas de sus cuerpos, emancipadas gracias a su uso de la biología y del destino de maternidades repetidas y casi inevitables.

De allí que se produjera una auténtica inversión en los términos bajo los cuales había sido concebido el tema hasta ese momento [...] (Ciriza, 2013, p. 68).
\end{abstract}

Así, las feministas de los 70 instalaron el debate sobre las tramas de significación que legitimaban y naturalizaban el orden social establecido. "La crítica feminista fue subversiva. Apuntó hacia puntos nodales del sentido común dominante al poner en tela de juicio el lugar asignado a los varones en el orden político, simbólico, familiar" (Ciriza, 2007, p. 7).

Durante la década del 80 , se intensificaron los activismos feministas con campañas de denuncia y sensibilización y con propuestas de intervención estatal y de normativas específicas (Gamba, 2008). A pesar de este marco favorable para la ampliación de derechos, en Argentina se produjo un silenciamiento de la lucha por el derecho al aborto. Ciriza (2013) aduce que la principal causa fue el triunfo ideológico-político de "la Iglesia católica y grupos de civiles fundamentalistas" (p. 73) que lograron instalar una equivalencia entre la noción de "lucha en favor de la despenalización o legalización del aborto" " "lucha a favor del aborto". En sus palabras: 


\begin{abstract}
El deslizamiento de sentido que equiparó aborto a cultura de la muerte, y el posicionamiento de estos sectores como defensores de "la vida", colocó en el debate público una polaridad difícil de desmontar entre "antiabortistas pro-vida" y "abortistas", como han sido calificadas quienes defienden la legalización y /o la despenalización del aborto [...]. La apelación a la vida, a la imagen de la maternidad esplendorosa, a la fragilidad de los inicios de la vida humana, y la asimilación entre aborto y asesinato, son armas poderosas que han dado a estos grupos la iniciativa en el debate (Ciriza, 2013, pp. 73-74).
\end{abstract}

En efecto, el discurso católico que se plasma en la Declaración sobre el aborto de 1974 impuso el concepto del "derecho a la vida" como algo dado de antemano; con ello, deslegitimó cualquier discusión política acerca de lo que se consideraba vida y postergó la discusión sobre el derecho al aborto seguro (Morán Faúndes, 2013).

El catolicismo integral, en su defensa de la sexualidad sujeta a la procreación, de la maternidad tradicional como base de la identidad femenina, de la negación a las diferentes formas de vivir la sexualidad, se basa en y al mismo tiempo refuerza al patriarcado (Di Marco, 2010, p. 56)

Durante esa década, la mortalidad gestacional por aborto aumentó considerablemente respecto a la registrada en los años anteriores (Torrado, 2003).

Luego, en los 90, las feministas latinoamericanas concretaron tres conferencias clave: la de Población y Desarrollo (El Cairo, 1994), la Interamericana para Prevenir, Sancionar y Erradicar la Violencia contra la Mujer (Belém do Pará, Brasil, 1994) y la de la Mujer (Beijing, 1995), en las que reinstalaron la lucha por la regulación de los delitos de género (Saccomano, 2017) y por la definición de lo que implicaba el ser mujer a partir de dos preguntas clave: se trata de ser “ ¿madre o ciudadana?, ¿ receptáculo de una nueva vida o sujeto con derechos?” (Lamas, 2008, p. 71). Posteriormente, distintos países de la región adoptaron diferentes posturas favorables para incorporar a las mujeres en las políticas de desarrollo (Di Marco, 2010). Además, durante esa década, comenzó el proceso de institucionalización del feminismo y se impuso la perspectiva de género en las políticas públicas y en el ámbito académico para cuestionar las relaciones de subordinación entre varones y mujeres (Ciriza, 2007). También, las feministas crearon redes nacionales contra la violencia hacia las mujeres en numerosos países. Además, se reactivó el reclamo por el derecho al aborto, que alcanzó su máxima expresión durante el V Encuentro Feminista Latinoamericano y del Caribe (1990), que se desarrolló en la localidad argentina de San Bernardo (Di Marco, 2010). Allí, se redactó la declaración a favor del aborto como derecho y se instauró el 28 de septiembre como el Día del derecho al aborto de las mujeres de América Latina y el Caribe (Ciriza, 2013). Asimismo, se lanzó una campaña por el derecho al aborto en el marco de los derechos humanos, que se realiza desde 1993 en 18 países de la región (Di Marco, 2010).

Específicamente en Argentina, la práctica política se vio atravesada por la incorporación de nuevas actoras sociales provenientes de los movimientos populares. Sus 
Paola Ingrassia

La constitución de la violencia de género como problema público y los frames sobre aborto: revisión crítica de antecedentes y propuesta de análisis

activismos "dieron como resultado la emergencia de un feminismo popular que surge de la participación de las mujeres en diferentes espacios de lucha y en especial en los Encuentros Nacionales de Mujeres" (Di Marco, 2010, p. 54). La crítica política de estos movimientos al orden patriarcal, entendido como un orden político que determina las relaciones de poder a favor de los varones (Lagarde, 1996), obtuvo grandes logros a lo largo de los últimos años. En 2009, durante el Gobierno de Cristina Fernández, se sancionó la Ley 26485 de Protección Integral a las Mujeres para prevenir, sancionar y erradicar la violencia contra las mujeres, más conocida como "Ley de violencia de género". La norma creó la figura jurídica de la violencia simbólica como uno de los tipos de violencia establecidos, y la violencia mediática como una de sus manifestaciones. La primera se refiere a los patrones estereotipados (mensajes, valores, íconos o signos) que transmiten y reproducen dominación, desigualdad y discriminación en las relaciones sociales. La segunda alude a las publicaciones o difusiones de mensajes e imágenes estereotipados a través de cualquier medio masivo de comunicación que promuevan la explotación de mujeres o atenten contra su dignidad. Su fin es lograr un abordaje integral y multidisciplinario de la violencia de género.

Ese mismo año, se sancionó la Ley 26522 de Servicios de Comunicación Audiovisual, que determina en uno de sus artículos que los contenidos radiales y televisivos deben respetar la Ley de violencia de género. Además, prevé promover una imagen equilibrada y variada de las mujeres y los hombres en los medios de comunicación, la protección y salvaguarda de la igualdad entre hombres y mujeres y el tratamiento plural, igualitario y no estereotipado a fin de evitar toda discriminación por género u orientación sexual.

Luego, en 2012, el Congreso aprobó la Ley 26791, que incorpora al femicidio en el Código Penal como agravante de la figura de homicidio. De esa forma, se eliminan atenuantes -como la emoción violenta-y se imponen penas más duras para los casos de violencia de género.

También, en diciembre de ese año, se inauguró el Consejo Federal contra la Trata de Personas, un espacio institucional para el seguimiento de todos los temas vinculados a la lucha contra la trata, y se habilitó la línea gratuita 145 para recibir denuncias desde cualquier punto del territorio nacional las 24 horas del día.

$\mathrm{Al}$ año siguiente, se creó la línea 144 para brindar atención, contención y asesoramiento en situaciones de violencia por razones de género y cumplir con los objetivos establecidos por la Ley 26485.

En este marco de normas que apuntan a prevenir la violencia de género en todas sus formas, en 2018 se sancionó la Ley Micaela o Ley 27499 de Capacitación Obligatoria en Género para todas las personas que integran los poderes Ejecutivo, Legislativo y Judicial de la Nación. El proyecto surgió luego del femicidio de Micaela García, una 
Austral Gmunicación

Volumen 9, número 2 (Diciembre de 2020):519-551. ISSN 2313-9129

joven militante del movimiento Ni Una Menos que fue asesinada en Gualeguay en 2017 por un hombre con antecedentes de ataques sexuales. La normativa prevé la creación del Programa Nacional Permanente de Capacitación Institucional en Género y Violencia contra las Mujeres. Su objetivo es sensibilizar y capacitar en perspectiva de género a todos los funcionarios públicos, sin distinción de jerarquía, forma de contratación ni ámbito en el que desempeñen sus funciones.

Así, muchas de las definiciones que hicieron los movimientos feministas sobre la situación de inequidad social que padecían las mujeres se volvieron tema de conflicto en la arena de la atención pública. Sin embargo, esa legitimación social es aún insuficiente para lograr la consolidación de los derechos de la mujer, tal como se desarrollará en los próximos apartados.

\section{Los eventos críticos que legitimaron el ciberactivismo feminista en Argentina}

El análisis de los eventos críticos, entendidos como aquellos acontecimientos que rompen de manera brusca las rutinas a las que la sociedad está acostumbrada (Staggenborg, 1993) y que enfocan la atención pública con el fin de redefinir un problema social (Pride, 1995), cobra especial relevancia para comprender las estrategias feministas en Argentina durante los últimos años.

A nivel nacional, los movimientos feministas propiciaron dos eventos críticos para impulsar la acción política en redes sociales. El primero fue en 2015 y resultó decisivo para la legitimación social de la violencia contra las mujeres como un problema público. El segundo tuvo lugar en 2018 e instaló en la arena de disputa de sentidos un tema central para la lucha feminista: la interrupción voluntaria del embarazo (IVE).

Durante 2015, la violencia de género se convirtió en uno de los temas de debate de la opinión pública y surgió en las redes sociales una masiva convocatoria impulsada por distintos colectivos de activistas feministas, comunicadoras y artistas nacionales. Luego del femicidio de Chiara Páez, una joven embarazada de 14 años que fue asesinada a golpes y enterrada por su novio en Rufino, provincia de Santa Fe, distintas ONG alertaron sobre el incremento del número de víctimas de femicidio, que pasó de 277 en 2014 a 286 en 2015 (La casa del encuentro, 2015). El repudio social contra la violencia hacia la mujer y los reclamos por la equidad de género alcanzaron su máxima expresión el 3 de junio de ese año, cuando miles de mujeres se reunieron en las principales plazas de todo el país para reclamar por la aplicación de políticas públicas concretas en materia de género. Bajo el hashtag \#NiUnaMenos, se lanzó una convocatoria nacional por Twitter y Facebook que logró traspasar los límites de las redes sociales y ganar un lugar privilegiado en los medios tradicionales. En ese proceso, prevaleció la necesidad de construir una identidad política colectiva bajo un eslogan de amplio alcance. “\#iUnaMenos se orientó a visibi- 
Paola Ingrassia

La constitución de la violencia de género como problema público y los frames sobre aborto: revisión crítica de antecedentes y propuesta de análisis

lizar e instalar nociones tales como violencia machista en lugar de conceptos propios de los ámbitos de producción de saber académicos tales como 'heteropatriarcado"' (Rosales, 2018, p. 73). Desde allí, los marcos de significación motivaron a la acción colectiva a partir del reclamo de acciones estatales concretas para frenar la así definida violencia machista y, en términos generales, el énfasis se puso en la necesidad de propiciar un cambio cultural para erradicar esta problemática de la sociedad. En esa línea, el marco de diagnóstico se identificó con la cultura machista (De Beauvoir, 1949) como legitimadora de prácticas violentas cuya máxima expresión es el femicidio. "La palabra 'femicidio' es, además, una categoría política, es la palabra que denuncia el modo en que la sociedad vuelve natural algo que no lo es: la violencia machista. Y la violencia machista es un tema de Derechos Humanos" (Colectivo Ni Una Menos, 2015). La propuesta de solución de los movimientos involucrados fue generar mecanismos integrales a partir del trabajo articulado entre el Estado y las organizaciones feministas. En lo concreto, las estrategias se concentraron en exigir: la instrumentación en su totalidad y con la asignación de presupuesto acorde a la Ley 26485 de protección integral para prevenir, sancionar y erradicar la violencia contra las mujeres en los ámbitos en los que desarrollen sus relaciones interpersonales; la recopilación y publicación de estadísticas oficiales sobre violencia hacia las mujeres, incluyendo los índices de femicidios; la apertura y el funcionamiento pleno de Oficinas de Violencia Doméstica de la Corte Suprema de Justicia en todas las provincias; la federalización de la línea 137; y las garantías para la protección de las víctimas de violencia, para el acceso a la Justicia y para el cumplimiento del derecho de la niñez con un patrocinio jurídico especializado y capacitado en la temática. Además, las activistas reclamaron la incorporación y profundización en todos los currículos educativos de la educación sexual integral con perspectiva de género (Colectivo Ni Una Menos, 2015). "En tanto lema, colectivo feminista y movimiento social, Ni Una Menos forma parte de un continuum de narrativas feministas que permiten a otras acceder a aquello que el relato oficial y patriarcal invisibiliza" (Alcaraz, 2020, s.n.).

En 2018, se produjo el segundo evento crítico que se considera trascendental en este mapeo sobre la historia reciente de la lucha feminista argentina. Ese año se realizó una movilización nacional de gran alcance bajo el hashtag \#AbortoLegalYa por el derecho a la IVE.

La Campaña Nacional por el Derecho al Aborto Legal, Seguro y Gratuito (CNDALSG) se inició en 2004 y tomó estado público el 28 de mayo de 2005, Día Internacional de Acción por la Salud de las Mujeres (Gutiérrez, 2014). Sin embargo, recién en 2018 el proyecto para legalizar la interrupción voluntaria del embarazo obtuvo media sanción en la Cámara de Diputados. Posteriormente, fue rechazado en la Cámara de Senadores. Desde entonces, el derecho al aborto se convirtió en un tema central para las agendas mediática, pública y política y en uno de los hashtags más 
utilizados en las redes sociales: \#seráley. La identificación colectiva a favor de la legalización del aborto también se logró a través del pañuelo verde, cuyo fin fue resignificar el blanco de las Madres y Abuelas de Plaza de Mayo (Di Marco, 2010).

\section{Análisis de los frames noticiosos sobre el aborto}

Si los individuos definen una situación como real, esa situación es real en sus consecuencias (Thomas, 2005, p. 27).

Al igual que para los teóricos de los movimientos sociales, en el campo de estudio de los encuadres periodísticos la idea de Goffman (1974), que afirma que todo está determinado socialmente, es clave para comprender al framing como un proceso dinámico e interactivo de creación y transmisión de significados que atraviesa todas las instancias de la comunicación (D’Angelo, 2012). Allí, los frames o encuadres noticiosos se conciben como una de esas instancias y representan el punto de partida para estudiar y comprender las distintas formas en las que se presenta una realidad (Entman, 1993).

[...] las definiciones de una situación se forjan de acuerdo con principios de organización que gobiernan los eventos -al menos, los sociales- y nuestra relación subjetiva con ellos; frame es la palabra que uso para referirme a tales elementos básicos que soy capaz de identificar (Goffman, 1974, p. 10).

Si bien las investigaciones tradicionales se han interesado por vincular la noción de "marco" con la sociología y la de "encuadre" con el área de la comunicación, la fusión entre ambas posturas y el traslado de conceptos entre las disciplinas es evidentemente posible (Sádaba, 2008). En efecto, en los medios de comunicación, los frames funcionan como faros y "los hechos toman su significado al ser enmarcados de alguna manera" (Gamson, 1992, p. 120). En ese sentido, en el estudio de un texto, los encuadres se manifiestan por la presencia o ausencia de ciertas palabras clave, frases comunes, imágenes estereotipadas, fuentes de información y oraciones que proporcionan grupos de hechos o juicios que refuerzan temáticamente (Entman, 1993). Así, los frames noticiosos que remiten al contenido de los discursos periodísticos son construcciones latentes que pueden identificarse a partir del agrupamiento de ciertos indicadores manifiestos que aparecen en los textos. En palabras de Entman (1993), los contenidos noticiosos promueven una definición particular de un problema específico con la que determinan un agente causal, junto con sus costos y beneficios. A la vez, diagnostican sus causas, es decir, identifican las fuerzas que lo originaron (sean factores o agentes) y atribuyen una responsabilidad. Simultáneamente, emiten juicios morales, por lo tanto, distinguen lo que debe considerarse bueno de lo que debe entenderse como malo. Por último, sugieren un tipo de tratamiento para el problema tal como ha sido definido $y$, 
con ello, pueden predecir los efectos más probables o exponer una propuesta de solución. Desde este enfoque, los textos noticiosos son construcciones en las que la política, los problemas y los eventos se definen a partir de diferentes patrones de selección e interpretación (Matthes, 2012). Más aún, esas interpretaciones de los problemas se negocian, impugnan y modifican con el tiempo.

\begin{abstract}
Para dar un ejemplo, el tema del aborto puede enmarcarse como la muerte de vidas humanas no nacidas o puede verse desde la perspectiva de la libre elección. Ambos puntos de vista implican diferencias en cuanto a la definición del problema, la interpretación causal, la evaluación moral y la recomendación de tratamiento (Matthes, 2012, p. 249). ${ }^{5}$
\end{abstract}

En efecto, si entendemos que la elaboración de sentido de los acontecimientos es una construcción social de la cual forman parte los medios de comunicación (Pride, 1995) y que estos son una de las arenas competitivas (Hilgartner y Bosk, 1988) que interviene en la disputa por el significado atribuido a los problemas sociales, cobra especial relevancia el análisis de los encuadres específicos que la agenda mediática ofreció sobre el derecho al aborto. El objetivo, entonces, es analizar los frames noticiosos que los principales medios digitales del país (Aguirre, 2020; Universidad de San Andrés, 2020) -Infobae, Clarín y La Nación- utilizaron para construir las noticias sobre aborto. En lo específico, se estudian los elementos constitutivos de las notas en las que el aborto fue el tema central y que fueron publicadas por los tres medios descriptos durante las semanas posteriores al día en el que dos eventos críticos instalaron el debate en las agendas públicas, mediáticas y políticas de 2018 y 2020. Esto es, durante la semana posterior al 6 de marzo de 2018, cuando se presentó en la Cámara de Diputados el proyecto de ley sobre la interrupción voluntaria del embarazo, hasta el 12 de marzo de ese año. Y durante las dos semanas posteriores al 3 de agosto de 2020, cuando el debate por el derecho al aborto se instaló nuevamente en el centro de la opinión pública luego de que el jefe de Gobierno porteño, Horacio Rodríguez Larreta, avalara oficialmente la aplicación del protocolo de interrupción legal del embarazo (ILE) ${ }^{6}$ en la Ciudad de Buenos Aires. Para el estudio, se consideraron todas las secciones, excepto las cartas de lectores/as, los suplementos y las críticas cinematográficas.

En el marco de los conceptos precedentes, se elaboró una matriz de análisis que triangula las nociones teóricas de Snow y Benford $(1988,1992)$, con las de Entman (1993) y con los enfoques de género (De Beauvoir, 1949; Millett, 1975; Wollstonecraft,

\footnotetext{
Traducción propia

6 Este derecho se contempla desde la segunda reforma del Código Penal en 1921 (artículo 86) para los casos en los que el embarazo represente un peligro para la vida o para la salud de la madre y en los que provenga de una violación. Además, en diciembre de 2019, el Ministerio de Salud de Argentina anunció el protocolo ILE, que reafirma las causales previstas en el Código Penal argentino y confirmadas por la Corte Suprema de Justicia en 2012, confirmando la legalidad de la interrupción del embarazo si este es la consecuencia de una violación o si implica riesgos para la vida o para la salud de la mujer gestante.
} 
1998). La estrategia se centra en un análisis de contenido, técnica que se considera apropiada para establecer la relevancia que adquieren ciertos temas o atributos en la agenda de los medios (Aruguete, 2016). “[...] el análisis de contenido es una técnica de investigación que permite descubrir el ADN de los mensajes mediáticos, dado que dicho análisis permite reconstruir su arquitectura, conocer su estructura, sus componentes básicos y el funcionamiento de los mismos [...]" (Igartua, 2006, p. 181). (Ver tabla 1).

\title{
Resultados
}

En total se analizaron 64 noticias sobre aborto. En la semana comprendida entre el 6 y el 12 de marzo de 2018, Infobae publicó 5 notas en las que el aborto fue el tema central, Clarín 19 y La Nación 16. Luego, entre el 3 y el 16 de agosto de 2020, Infobae publicó 6 notas, mientras que Clarín y La Nación publicaron 9 cada uno.

En el primer período analizado, en las 5 notas publicadas por Infobae se observó que el medio definió a la aplicación de la IVE como justa o necesaria y que la causa de la situación problemática era el vacío estatal para cumplir con los derechos pendientes de las mujeres. Además, atribuyó las responsabilidades del problema al Estado/ Gobierno. En el mismo sentido, expuso propuestas de solución vinculadas a resolver las deudas pendientes del Estado en materia de derechos de género. En esa línea, el medio utilizó frames basados en las siguientes ideas:

\begin{abstract}
"La sociedad y el Estado deben debatir este problema y encontrar soluciones que den respuesta a un problema que no puede continuar en el campo de la clandestinidad y de la negación en su importancia socio-sanitaria", se sostiene en los argumentos del proyecto (Tesei, 2018).

De la campaña participaron más de 30 médicos, médicas y agentes sanitarios de todo el país, que fueron convocados por el colectivo para, "más allá de celebrar el debate parlamentario por primera vez en el Congreso", que sean los protagonistas. "Entendemos principalmente que la legalización del aborto es un tema de salud pública y son ellos quienes mejor pueden explicar desde su cotidianidad de qué manera se atiende a mujeres que llegan por abortos en transcurso realizados de manera ilegal y clandestina, ya sea pagando mucho dinero o no", amplió Ojeda (Chávez, 2018).
\end{abstract}

Entre las 19 notas publicadas por Clarín se observaron algunas diferencias. En 15 se definió a la IVE como un derecho necesario, mientras que en 4 se la presentó como dañina. Las causas de la situación problemática se vincularon al vacío estatal en 13 publicaciones, y en 6 se consignó que detrás del proyecto de ley existían intereses de sectores específicos para obtener beneficios puntuales con la medida. Por ejemplo, se apuntó que el fin fue distraer la atención pública en un momento complicado para el Gobierno de Mauricio Macri. "De todas formas, los obispos están convencidos de que el desbloqueo parlamentario del tema es 'una cortina de humo' para tapar los problemas económicos y su repercusión social” (Rubin, 2018). 
Paola Ingrassia

La constitución de la violencia de género como problema público y los frames sobre aborto: revisión crítica de antecedentes y propuesta de análisis

Tabla 1. Matriz de análisis con operacionalización de variables

Medio: se escribe en cursiva el nombre completo del medio bajo análisis.

Titulo: se transcribe textualmente el título de la unidad de análisis.

Fecha: se especifica día, mes y año en el siguiente orden: $\mathrm{dd} / \mathrm{m} \mathrm{m} / \mathrm{aaaa}$

Autor/a: se aclara nombre y apellido tal como figura en la noticia.

Si no se especifican esos datos, se consigna N/E.

Link: https://doi.org/xx.xxxxxxxxxx

Número de ficha: se establece un número para cada nota.

Los frames noticiosos sobre aborto Puntaje: se consigna el código que

corresponda a la variable observada.

\section{Marco de diagnóstico}

1.1. ¿Cuál es la definición que se hace del problema? Determinar cuál de las siguientes opciones es la que mejor refiere el marco construido en términos de

evaluación moral a partir del uso de expresiones concretas y palabras clave.

$1=$ La aplicación de la IVE/LLE se define como justa o necesaria.

$2=$ La aplicación de la VE/LLE se define como injusta o dañina.

1.2. ¿Cuáles son las causas que se identifican como responsables u originarias de

problema? Elegir la opción que corresponda (únicamente puede ser una opción):

$1=$ Vacío estatal para cumplir con los derechos pendientes de las mujeres.

$2=$ Sacar rédito político o beneficios puntuales con una medida específica.

$3=$ Atentar contra la sociedad

1.3. ¿Quién/es se define/n como responsable/s de la situación problemática? Utilizar

los siguientes códigos según predominen sus referencias latentes o manifiestas:

$1=$ El Estado/el Gobierno

$2=$ El sistema/orden patriarca

$3=$ Las mujeres/un sector minoritario

\section{Marco de pronóstico}

2.1. ¿Cuál es la propuesta de solución que se presenta? Establecer cuál de las siguientes opciones es la que mejor refiere el marco construido en torno a la propuesta

de solución que se expone para el problema tal como ha sido definido:

$1=$ Resolver las deudas pendientes del Estado en materia de derechos de género.

$2=$ Reclamar la atención pública para modificar la situación de injusticia actual contra las mujeres.

$3=$ Condenar a las mujeres y/0 a los/as políticos/as a favor de la ley.

\section{Marco motivacional}

3.1. ¿Cuál es el énfasis de la nota? Se refiere a la intención general de la noticia a parti del uso de estrategias lingüísticas, fuentes destacadas, omisiones, metáforas y otros

recursos que den cuenta del sentido latente. Elegir la opción que corresponda para evaluar

el foco de la nota y definir si apunta a conseguir la adhesión de su público para:

$1=$ Cambiar las condiciones actuales en materia de derechos de género.

$2=$ Pronunciarse en contra de la IVE, ILE 0 el aborto.

\section{Estrategias discursivas}

Se transcriben textualmente las frases y recursos más significativos que den cuenta de los marcos analizados.

Observaciones: se consignan consideraciones específicas a destacar.

Fuente: elaboración propia. 
La despenalización del aborto, que copó la agenda social y política, fue parte del temario que se discutió en Parque Norte. En el macrismo no maquillan las diferencias internas que abrió la discusión. Al contrario, les dieron publicidad como una muestra de su democracia interna y del diálogo que pretenden erigir (Carelli Lynch, 2018).

En el mismo sentido, en 13 publicaciones se responsabilizó al Estado de retrasar un derecho de las mujeres; y en 6 , a un sector minoritario de impulsar un proyecto cuyo fin era sacar rédito político. En cuanto a las propuestas de tratamiento, en 14 notas se observó la necesidad de resolver las deudas pendientes del Estado en materia de derechos de género, en 2 se enfatizó el reclamo de la "atención pública" para modificar la situación de injusticia actual contra las mujeres y en 3 se advirtió un marco punitivista contra la mujer, las feministas o los/as políticos/as que estaban a favor del proyecto de ley. En coherencia con los marcos anteriores, en 15 notas el foco de atención apuntó a conseguir la adhesión del público para cambiar las condiciones imperantes en materia de derechos de género. A modo de ejemplo, se seleccionaron las siguientes estrategias que dan cuenta de los frames construidos en torno al aborto.

1. Frames que enfatizan la necesidad de cambiar las condiciones actuales en materia de derechos de género

Uno de los carteles de los que se leen en este salón colmado del Anexo de Diputados del Congreso Nacional dice: "El aborto legal es la gran deuda de la democracia". Unas doscientas mujeres, la mayoría de ellas con el pañuelo verde que identifica a la Campaña Nacional por el Derecho al Aborto Legal, Seguro y Gratuito, están aquí para dar su apoyo a la séptima presentación del proyecto de ley de Interrupción Voluntaria del Embarazo. Aplauden, sonríen, cantan "Aborto legal / en el hospital" y "Anticonceptivos para no abortar / aborto legal para no morir" [...] Victoria Donda, la primera legisladora en hablar en la conferencia de prensa de presentación del proyecto. Y agrega: "Ese debate es entre el aborto legal, seguro y gratuito, y el aborto clandestino que hace que mueran mujeres jóvenes y pobres. La última a la que le conocimos el nombre es María Campos, con cinco hijos y Santiago del Estero. Murió por practicarse un aborto en condiciones inseguras. Esta ley se llama 'María Campos"' (Roffo, 2018).

En primer lugar consideran que la legislación "debe adecuarse a la realidad", es decir, que el aborto es "una práctica socialmente vigente" en la Argentina, "como en casi todo el resto del mundo", y la principal consecuencia de su penalización es "poner en riesgo la vida de las mujeres que no pueden acceder a los cuidados necesarios porque no disponen de recursos suficientes" (Funcionarios y referentes oficialistas..., 2018).

\section{Frames construidos en contra de la IVE}

El arzobispo de La Plata cuestionó a Mauricio Macri, al considerar que "un verdadero político no debe ni puede hacer eso" [...] El punto es la aparente ambigüedad, según el religioso, de encausar institucionalmente una discusión pero retirando el respaldo a la cuestión de fondo, esto es despenalizar el aborto. Las palabras del prelado: "La democracia no es cualquier cosa. Democracia no es decir 'yo estoy en contra del aborto, pero que se discuta"'. "No es así. Un verdadero político no debe ni puede hacer eso”, explicó Aguer (Lara, 2018). 
Entre las 16 notas que publicó La Nación, 9 definieron a la IVE como justa o necesaria y 7 como injusta o dañina para la sociedad. Asimismo, 9 noticias atribuyeron al vacío estatal las causas de la problemática, 2 vincularon a la promoción del proyecto de ley con los intereses de un sector político por obtener beneficios puntuales y 5 afirmaron que la causa originaria de la IVE era atentar contra la sociedad. "Para Bullrich, el embarazo no deseado es el problema: 'El Estado debe prevenir los problemas, atacar las causas y defender la vida siempre" (Esteban Bullrich: "No estoy de acuerdo..., 2018). En la misma línea, 10 notas definieron como responsable de la situación problemática al Estado/Gobierno y 6 les atribuyeron la responsabilidad de atentar contra la sociedad a las feministas que impulsaban la ley o a un sector político que fue presentado como minoritario, como un grupo que no representaba a la sociedad.

En el análisis del marco de pronóstico, la propuesta de solución que se presentó en 7 noticias apuntó a resolver las deudas pendientes del Estado en materia de derechos de género; en 2, a reclamar la atención pública para modificar la situación de injusticia actual contra las mujeres y en 7 se construyeron marcos punitivistas que apuntaron a condenar a las mujeres y/o a los/as políticos/as que estaban a favor del proyecto de ley. Para sostener lo anterior, se seleccionaron los siguientes ejemplos que evidencian los énfasis de las noticias estudiadas.

1. Frames que enfatizan la necesidad de cambiar las condiciones actuales en materia de derechos de género

En el texto, los intelectuales ligados al Gobierno parten del hecho de que la legislación debe adecuarse a una realidad: "Que el aborto es una práctica socialmente vigente en nuestro país, como en casi todo el resto del mundo, y la principal consecuencia de su penalización es poner en riesgo la vida de las mujeres que no pueden acceder a los cuidados necesarios porque no disponen de recursos suficientes" (Veneranda, 2018).

Consultado por LA NACION, el abogado constitucionalista, Andrés Gil Domínguez dijo: "Argentina fue pionera en legislar el aborto porque desde principios del siglo XX la sociedad entendió que ante la colisión de derechos entre la mujer y la persona por nacer (a pesar de que el Código Civil establecía que había vida a partir del momento de la transacción en el seno materno) prevalecían los derechos de la mujer. Prevalecían el derecho a la vida, la salud y la libertad sexual, que es cuando una mujer queda embarazada producto de una violación. La sociedad argentina resolvió, a través de sus representantes, despenalizar el aborto en estas cuestiones porque era en este tema una sociedad adelantada" (Costa, 2018).

\section{Frames que apuntan a movilizar a su público en contra de la IVE}

La doctora Gerace explicó que, en efecto, la ciencia sostiene que la vida comienza con la unión del óvulo y el espermatozoide. Luego precisó que durante los primeros días de gestación se produce un intercambio de material genético que le otorga su identidad al embrión: "Aquello que nos hace únicos" (Cómo se organizan..., 2018). 


\begin{abstract}
Pero esas definiciones arbitrarias no habilitan a terminar con vidas de seres vivos cuya esencia humana les permitirá seguir desarrollándose como solo los humanos pueden, con razón, libertad, sociabilidad y amor, hasta su muerte (Pinedo, 2018).
\end{abstract}

En las semanas posteriores al segundo evento definido como crítico, es decir, entre el 3 y el 16 de agosto de 2020, Infobae publicó 6 notas sobre la interrupción legal del embarazo, mientras que Clarín y La Nación publicaron 9. Los frames construidos presentan algunas diferencias y similitudes con el período anterior. La aplicación de la ILE se definió como justa o necesaria en 3 de las notas publicadas por Infobae, en 6 de las publicaciones de Clarín y en 4 de La Nación.

En los casos en los que Infobae definió que la aplicación de la ILE era justa o necesaria, estableció que la causa de la situación problemática era el vacío estatal para cumplir con los derechos pendientes de las mujeres y que el responsable era el Estado (o el Gobierno) y/o el sistema patriarcal. En esa línea, la propuesta de solución apuntó a resolver las deudas estatales pendientes en materia de derechos de género. "Este año la excusa es la pandemia; el próximo, seguramente lo serán las elecciones. Las mujeres debemos seguir exigiendo que sea ley" (Del Pla, 2020). Sin embargo, en el resto de las notas, el medio construyó marcos punitivistas contra las mujeres y/o contra los/ as políticos/as que estaban a favor de la ILE. "La fecha elegida evoca el 8 de agosto de 2018, cuando el Congreso de la Nación, con el apoyo de millones de personas que se movilizaron en todo el país, detuvo la legalización del aborto" (A 2 años del NO..., 2020); "La gran paradoja de estos tiempos de pandemia [...] es que se escuchen muchas voces promoviendo el aborto como un derecho de la mujer, desatendiendo tanto el sentido común como la legislación de nuestro país" (Menem, 2020); “[...] las organizaciones provida celebran el Día Internacional de Acción por las 2 Vidas, fijado a partir de la decisión del Senado argentino de rechazar el 8 de agosto de 2018 una iniciativa impulsada por colectivos feministas para legalizar el aborto" (Argentina recuerda el rechazo..., 2020).

También insistió en asociar a "los celestes" con "provida" y a "los verdes" (ni siquiera utilizó el artículo en femenino) con "proaborto". Este dato no es menor, ya que se plantea un binarismo que divide entre buenos/as y malos/as o entre quienes están a favor de la vida y quienes no.

Debido a las restricciones del aislamiento social obligatorio que rigen en Argentina por la pandemia de coronavirus, las acciones de los "celestes" y los "verdes" - colores con los que se han identificado los movimientos provida y proaborto, respectivamente- se centran este sábado en las redes sociales (Argentina recuerda el rechazo..., 2020).

En Clarín, en cambio, se destacaron los frames a favor del derecho de la mujer para decidir sobre su propio cuerpo. En la mayoría de las notas, el medio definió que el 
Paola Ingrassia

La constitución de la violencia de género como problema público y los frames sobre aborto: revisión crítica de antecedentes y propuesta de análisis

problema era la ausencia de una respuesta estatal ante los derechos pendientes de las mujeres y, por lógica, definió a la aplicación de la ILE como justa.

La indignación de los religiosos y conservadores no parece ser tal ante las violaciones de niñas. En su ideario, una niña no puede decidir interrumpir un embarazo no querido, pero sí consideran que una niña es suficientemente madura y fuerte como para soportar una violación, un embarazo, un parto, y luego la maternidad o la entrega del bebé nacido (Iglesias, 6 de agosto de 2020).

“[...] el tema atravesó como nunca antes a la sociedad argentina. Manifestaciones masivas, debates en los medios y una Campaña que logró que a nivel social se condene la penalización y el silencio" (Perciavalle, 2020); "Quienes rechazan la legalización también se oponen a los anticonceptivos, la educación sexual y la interrupción legal, que son leyes y derechos ya conquistados" (Iglesias, 8 de agosto de 2020).

En este periodo de análisis, La Nación es el que presentó la mayor cantidad de marcos punitivistas y sus construcciones ameritan mayores precisiones por la vinculación que impuso entre el derecho de las mujeres a abortar y las definiciones personales sobre los políticos de turno. Cuando el medio definió que la aplicación de la ILE era dañina o peligrosa, consignó que las causas del problema radicaban en la necesidad de atentar contra la sociedad y que el responsable de tal daño era el Estado/Gobierno. En coherencia con esto, la propuesta de solución fue condenar a los políticos y a los sectores que defendían la implementación de la norma y el énfasis de las notas recayó en rechazar la implementación de la ILE.

Varias organizaciones convocaron, también, para el sábado, a las 14, a una \#CaravanaProvida [...] el objetivo es revitalizar el impacto que produjo hace dos años el rechazo del Senado a la despenalización del aborto, en momentos en que el gobierno nacional tiene previsto enviar al Congreso un proyecto para impulsar nuevamente la legalización del aborto (Agrupaciones "celestes" recordarán..., 2020).

También insistió en que se trataba de una batalla entre "los verdes" (así, en masculino) y "las dos vidas". "[...] varias organizaciones en 'defensa de las dos vidas' celebraron los dos años de la sesión en que el Senado rechazó el proyecto de despenalización del aborto, que dividió aguas en la sociedad [...] Reclamo de "los verdes' [...]" (Con una caravana..., 2020). Es decir, la valoración positiva claramente recayó en el grupo asociado a la vida, "los celestes", "los provida", mientras que "los verdes" (las verdes) ocuparon el lugar de la otredad en medio de este orden patriarcal.

Ya pasaron dos años de la jornada histórica en la que el Senado de la Nación rechazó el proyecto que intentaba despenalizar el aborto. Ese debate mantuvo en vilo a toda la sociedad argentina y el resultado fue el fiel reflejo del pensamiento de la inmensa mayoría de los argentinos [...] El 8 de agosto fue un antes y un después de la militancia provida, de un año intenso en el que Argentina rompió dos veces el récord de la mayor marcha por la vida; lanzamos el pañuelo celeste como emblema internacional provida y nos cons- 


\begin{abstract}
tituimos como país emblema de la lucha en defensa de las dos vidas, motivando a otras naciones a asumir igual compromiso en el cuidado y respeto del derecho humano a la vida, especialmente de los más débiles, pero también de las madres (Magnasco, 2020).
\end{abstract}

En la Tabla 2, se muestran los resultados generales del análisis sobre los frames noticiosos construidos en torno al aborto entre 2018 y 2020 por Infobae, Clarín y La Nación.

Tabla 2. Frames noticiosos sobre aborto

\begin{tabular}{|c|c|c|c|c|c|c|c|c|c|c|c|c|c|c|}
\hline & \multicolumn{8}{|c|}{ Marco de diagnóstico } & \multirow{2}{*}{\multicolumn{3}{|c|}{$\begin{array}{l}\text { Marco de pronóstico } \\
\text { Propuesta desolución }\end{array}$}} & \multirow{2}{*}{\multicolumn{2}{|c|}{$\begin{array}{l}\text { Marco motivacional } \\
\text { Motiva la adhesión }\end{array}$}} & \\
\hline & \multicolumn{2}{|c|}{ Definición del problema } & \multicolumn{3}{|c|}{ Causas } & \multicolumn{3}{|c|}{ Responsables } & & & & & & \\
\hline & Justa/nec. & Injusta/dañ. & Vacioestatal & Rédito pol. & Atentar $\mathrm{c} / \mathrm{soc}$. & Estado/Gob. & Sist. Patriarc. & Mujeres/s.min & Resolver deu. & Reclamar at. & Eondenarm/sn & Cambiar c.a. & a. Pron. en contrs & \\
\hline \multicolumn{14}{|c|}{2018} & 2018 \\
\hline Infoboe & 5 & 0 & 5 & 0 & 0 & 5 & 0 & 0 & 5 & 0 & 0 & 5 & 0 & 5 \\
\hline Clarin & 15 & 4 & 13 & 6 & 0 & 13 & 0 & 6 & 14 & 2 & 3 & 15 & 4 & 19 \\
\hline La Nación & 9 & 7 & 9 & 2 & 5 & 10 & 0 & 6 & 7 & 2 & 7 & 9 & 7 & 16 \\
\hline \multicolumn{14}{|c|}{2020} & 2020 \\
\hline Infoboe & 3 & 3 & 3 & 1 & 2 & 2 & 1 & 3 & 3 & 0 & 3 & 3 & 3 & 6 \\
\hline Clarin & 6 & 3 & 5 & 0 & 4 & 6 & 1 & 2 & 5 & 0 & 4 & 5 & 4 & 9 \\
\hline La Nación & 4 & 5 & 2 & 3 & 4 & 5 & 0 & 4 & 3 & 0 & 6 & 3 & 6 & 9 \\
\hline
\end{tabular}

Fuente: elaboración propia.

\title{
Conclusión
}

El análisis de los antecedentes históricos que constituyeron el carácter problemático de la violencia de género como problema público y de los eventos críticos que legitimaron el activismo feminista en redes sociales resulta sustancial para comprender los avances y desafíos pendientes en el campo de los derechos de género. En esa línea, la reflexión sobre la mirada particular que cada movimiento feminista consolidó en una situación específica permite, por un lado, visualizar la interacción dinámica y sostenida de las activistas feministas con la política y la cultura; por otro, establecer las reformulaciones necesarias para enfrentar los retos que impone el orden patriarcal.

Asimismo, el estudio de los frames noticiosos que intervinieron en la arena competitiva por imponer un sentido sobre el aborto resulta sustancial a la hora de deconstruir los resabios del legado patriarcal. En efecto, las noticias periodísticas ofrecen una forma de ver el mundo, construyen realidades, y su valor radica en la valoración social de un discurso autorizado que define situaciones problemáticas y atribuye responsabilidades. Desde este enfoque, la cantidad de notas publicadas por los principales medios digitales del país durante la semana en la que se presentó en la Cámara de Diputados el proyecto de ley sobre la interrupción voluntaria del embarazo (2018) da cuenta de la importancia periodística concedida al tema aborto. En ese momento, la frecuencia de aparición y los sentidos construidos en torno al derecho de las mujeres a decidir sobre el propio cuerpo pusieron de manifiesto la intención de los medios de influir en la arena de definición de problemas. En cambio, el número de publicaciones fue sig- 
Paola Ingrassia

La constitución de la violencia de género como problema público y los frames sobre aborto: revisión crítica de antecedentes y propuesta de análisis

nificativamente menor y el tema ocupó un lugar secundario durante las dos semanas posteriores al aval oficial de la aplicación del protocolo de interrupción legal del embarazo en la Ciudad de Buenos Aires (2020), a pesar de haberse extendido el período de análisis y del alerta de organizaciones internacionales sobre el impacto de la pandemia en la violencia contra las mujeres y niñas. Más aún, en ese escenario, numerosos tratamientos noticiosos invisibilizaron los derechos pendientes de las mujeres y consolidaron atribuciones de responsabilidad individuales en lugar de políticas o sociales. Así, las propuestas de solución recayeron en el punitivismo y en lo aparentemente aislado e intrascendente. De esa forma, se destaca la necesidad de propiciar investigaciones que focalicen en las disputas de sentido que se dan en las arenas competitivas entre distintos actores sociales. En consecuencia, sobresalen dos cuestiones a tener en cuenta. La primera es considerar las estrategias que los movimientos y contramovimientos se plantean en un contexto determinado a partir de oportunidades políticas y de ciertos eventos críticos. La segunda es comprender la interacción entre tales estrategias y los frames noticiosos a fin de interpretar las relaciones de poder que se plasman en los textos de los medios y las consecuencias sociales que ese proceso puede implicar.

\section{Referencias}

A 2 años del NO a la ley del aborto, convocan al Día Internacional de Acción por las Dos Vidas. (7 de agosto de 2020). Infobae. Obtenido de https://www.infobae. com/sociedad/2020/08/07/a-2-anos-del-no-a-la-ley-del-aborto-convocan-al-diainternacional-de-accion-por-las-dos-vidas/.

Agrupaciones "celestes" recordarán el sábado los dos años del rechazo al aborto con un encuentro virtual. (6 de agosto de 2020). La Nación. Obtenido de https://www.lanacion.com.ar/politica/ agrupaciones-celestes-recordaran-sabado-dos-anos-del-nid2413541.

Aguirre, M. (2020). Audiencia Digital Argentina: Covid-19 en Social Media. Comscore. Obtenido de https://www.comscore.com/lat/Prensa-y-Eventos/Infographics/ Audiencia-Digital-Argentina-Covid-19-en-Social-Media.

Ahora que sí nos ven. [@ahoraquesinosven]. (3 de agosto de 2020). 178 femicidios en 2020. [Publicación de estado]. Facebook. Obtenido de https:/www.facebook.com/263284224390602/ posts/608179523234402/?sfnsn=scwspwa\&extid=FbOJTzTRePhzuNN9.

Alcaraz, M. F. (2020). ¡Que sea ley!: La lucha de los feminismos por el aborto legal. Buenos Aires: Marea Editorial.

Amorós, C. (1991). Hacia una crítica de la razón patriarcal. Barcelona: Anthropos.

Argentina recuerda el rechazo parlamentario a la ley del aborto hace dos años. (8 de agosto de 2020). Infobae. Obtenido de https://www.infobae.com/america/ 
Austral Gmunicación

Volumen 9, número 2 (Diciembre de 2020):519-551. ISSN 2313-9129

agencias/2020/08/08/argentina-recuerda-el-rechazo-parlamentario-a-la-ley-delaborto-hace-dos-anos/.

Aruguete, N. (2016). The agenda setting hypothesis in the new media environment. Comunicación y Sociedad, (28), 35-58.

Beltrán, E., Maquieira, V., Álvarez, S. y Sánchez, C. (eds). (2008). Feminismos. Debates Teóricos Contemporáneos. Ciencias Sociales. Madrid: Alianza Editorial.

Belli, G. (2017). El sexo. El poder del pene. En Varela, N. Íbamos a ser reinas. Mentiras y complicidades que sustentan la violencia contra las mujeres (pp. 54-72). Books.

Blumer, H. (1971). Problemas sociales como comportamiento colectivo. Problemas sociales, 18(3), 298-306.

Brownmiller, S. (1981). Contra nuestra voluntad. Barcelona: Planeta.

Carelli Lynch, G. (9 de marzo de 2018). Inédito contrapunto a favor y en contra del aborto en el Congreso nacional del PRO. Clarín. Obtenido de https://www. clarin.com/politica/inedito-contrapunto-favor-aborto-congreso-nacional-pro_0_ HyEqFugFz.html.

Castro, R. y Riquer, F. (2003). La investigación sobre violencia contra las mujeres en América Latina: entre el empirismo ciego y la teoría sin datos. Cadernos de Saúde Pública, 19(1), 135-146. https://dx.doi.org/10.1590/S0102-311X2003000100015.

Chavez, V. (6 de marzo de 2018). Médicos de todo el país se unieron a \#NiUnaMenos para dar sus argumentos a favor de la legalización del aborto. Infobae. Obtenido de https:// www.infobae.com/tendencias/2018/03/06/medicos-de-todo-el-pais-se-unieron-ani-una-menos-para-dar-sus-argumentos-a-favor-de-la-legalizacion-del-aborto/.

Ciriza, A. (2007). Apuntes para una crítica feminista de los atolladeros del género. Estudios de filosofía práctica e historia de las ideas, 8(9), 1-22.

Ciriza,A.(2013). Sobre el carácter político de la disputa por el derecho al aborto. 30 años de luchas por el derecho a abortar en Argentina. En Zurbriggen, R. y Anzorena, C. (Comp.). El aborto como derecho de las mujeres. Otra historia es posible (pp. 63-83). Buenos Aires, Argentina: Herramienta.

Colectivo Ni Una Menos. (2015). Documento del \#NiUnaMenos. "Un nuevo nunca más". Revista Anfibia. Obtenido de http://revistaanfibia.com/cronica/ un-nuevo-nunca-mas/.

Cómo se organizan los que rechazan la legalización del aborto. (7 de marzo de 2018). La Nación. Obtenido de https://www.lanacion.com.ar/sociedad/la-resistenciacomo-se-organizan-los-que-rechazan-la-legalizacion-del-aborto-nid2114877/.

Con una caravana y un encuentro virtual, la defensa por "las dos vidas" reactivó en las calles el rechazo al aborto. (8 de agosto de 2020). La Nación. Obtenido de https://www.lanacion.com.ar/politica/ con-caravana-encuentro-virtual-sector-celeste-reactivo-nid2416158. 
Costa, J. M. (10 de marzo de 2018). Hace casi un siglo la Argentina fue pionera en legislar el aborto. La Nación. Obtenido de https://www.lanacion.com.ar/sociedad/ hace-casi-un-siglo-la-argentina-fue-pionera-en-legislar-el-aborto-nid2115915/.

Curiel, O. (2009). Descolonizando el feminismo: una perspectiva desde América Latina y el Caribe. Primer coloquio Latinoamericano sobre praxis y pensamiento feminista. Buenos Aires, Argentina.Obtenido de http://feministas.org/IMG/pdf/Ochy_Curiel.pdf.

Curtis, R. L., Jr. y Zurcher, L., Jr. (1973). Stable resources of protest movements: The multiorganizational field. Social Forces, 52, 53-61.

D’Angelo, P. (2012). Studying Framing in Political Communication with an Integrative Approach. American Behavioral Scientist, 56(3), 353-364.

De Beauvoir, S. (1981). El segundo sexo (1949). Buenos Aires: Siglo veinte.

De Gouges, O. (1791). Declaración de los Derechos de la Mujer y de la Ciudadana. Obtenido de https://www.culturamas.es/2012/09/07/declaracion-de-los-derechosde-la-mujer-y-de-la-ciudadana-1791-por-olympe-de-gouges/.

De Miguel,A. (2008). La violencia contra las mujeres. Tres momentos en la construcción del marco feminista de interpretación. Isegoría, (38), 129-137.

De Miguel Álvarez, A. (1994). El conflicto clase-sexo-género en la tradición socialista. En Amorós, C. (ed.). Historia de la teoría feminista (pp. 87-106). Madrid: Instituto de Investigaciones Feministas.

De Miguel Álvarez, A. (1995). Feminismos. En Amorós, C. (ed.). 10 palabras clave en mujer (pp. 217-225). España: Verbo Divino.

De Miguel Álvarez, A. (2003). El movimiento feminista y la construcción de marcos de interpretación. El caso de la violencia contra las mujeres. Revista Internacional de Sociología, 61(35), 127-150.

De Miguel Álvarez,A. (2005). La construcción de un marco feminista de interpretación: la violencia de género. Cuadernos de Trabajo Social, 18, 231-248.

Del Pla, R. (12 de agosto de 2020). Aborto legal: otra promesa incumplida. Infobae. Obtenido de https://www.infobae.com/opinion/2020/08/12/ aborto-legal-otra-promesa-incumplida/.

Di Marco, G. (2010). Los movimientos de mujeres en la Argentina y la emergencia del pueblo feminista. La Aljaba, XIV, 51-67.

Entman, R. M. (1993). Framing: Toward Clarification of a Fractured Paradigm. Journal of Communication, 43(4), 51-58.

Espinosa Miñoso, Y. (2016). De por qué es necesario a feminismo decolonial: diferenciación, dominación co-constitutiva de la modernidad occidental y el fin de la política de identidad. Solar. 12(1), 141-171. DOI: 10.20939/solar.2016.12.0109.

Esteban Bullrich: "No estoy de acuerdo con la legislación actual sobre el aborto". (6 de marzo de 2018). La Nación. Obtenido de https://www.lanacion.com.ar/politica/ 
esteban-bullrich-no-estoy-de-acuerdo-con-la-legislacion-actual-sobre-el-abortonid2114501/.

Femenías, M. L. (2011). Violencias del mundo global: inscripciones e identidades esencializadas. En Lagarde, M. y Valcárcel, A. Feminismo, género e igualdad (pp. 87-107). Madrid: Agencia Española de Cooperación Internacional al Desarrollo.

Funcionarios y referentes oficialistas, a favor de la despenalización del aborto. (7 de marzo de 2018). Clarín. Obtenido de https://www.clarin.com/politica/funcionariosreferentes-oficialistas-favor-despenalizacion-aborto_0_SJ9Yqa6Of.html.

Gamba, S. (2008). Feminismo: historia y corrientes. En Gamba, S. y Diz, T. (coord.). Diccionario de estudios de Género y Feminismos (pp. 2-8). Buenos Aires: Biblos.

Gamson, W. A. (1992). The social psychology of collective action. En Morris, A. D. y McClurg Mueller, C. (eds.). Frontiers in social movement theory (pp. 53-76). New Haven: Yale University Press.

Goffman, E. (1974). Frame Analysis: An Essay on the Organization of Experience. Londres: Harper and Row.

Gusfield, J. R. (1981). La cultura de los problemas públicos. En Weiner, C. La política del alcoholismo (pp. 55-60). Chicago: Universidad de Chicago.

Gusfield, J. R. (2014). Retórica y ciencia. La creación del orden cognitivo. En La cultura de los problemas públicos. El mito del conductor alcoholizado versus la sociedad inocente. Buenos Aires: Siglo XXI.

Gutiérrez, M. A. (2014). Aborto y ciudadanía: la Campaña Nacional por el Derecho al Aborto legal, seguro y gratuito en Argentina. Espacios Políticos. Obtenido de https://espaciospoliticos.org/aborto-y-ciudadania-la-campana-nacional-por-elderecho-al-aborto-legal-seguro-y-gratuito-en-argentina/.

Hilgartner, S. y Bosk, C. L. (1988). The rise and fall of social problems: A public arenas model. American Journal of Sociology, 94(1), 53-78.

Igartua, J. J. (2006) Métodos cuantitativos de investigación en comunicación. Barcelona: Bosch.

Iglesias, M. (6 de agosto de 2020). Aborto legal: niñas débiles para decidir, niñas fuertes para soportar. Clarín. Obtenido de https://www.clarin.com/opinion/aborto-legalninas-debiles-decidir-ninas-fuertes-soportar_0_x-ABL_G0z.html.

Iglesias, M. (8 de agosto de 2020). Aborto legal: quienes se oponen buscan retroceder, pero los derechos deben ser progresivos. Clarín. Obtenido de https://www. clarin.com/sociedad/aborto-legal-oponen-buscan-retroceder-derechos-debenprogresivos_0_jW9YlJNqH.html.

Jenkins, J. C. (1981). Sociopolitical movements. En Long, S. L. (ed.). Handbook of political behavior (Vol. 4, pp. 81-154). Nueva York: Plenum Publishers.

Kollontai, A. (1979). Memorias. Madrid: Debate. 
Paola Ingrassia

La constitución de la violencia de género como problema público y los frames sobre aborto: revisión crítica de antecedentes y propuesta de análisis

La casa del encuentro. (2015). Informes de Femicidios en Argentina Adriana Marisel Zambrano. Obtenido de http://www.lacasadelencuentro.org/femicidios03.html.

Lagarde, M. (1996). Género y feminismo. Desarrollo humano y democracia. Madrid: Horas y Horas.

Lagarde, M. (2000). Claves feministas para la autoestima de las mujeres. Madrid: Horas y Horas.

Lamas, M. (2008). El aborto en la agenda del desarrollo en América Latina. Perfiles Latinoamericanos, (31), 65-94.

Lara, R. (6 de marzo de 2018). Dura crítica de monseñor Héctor Aguer al Presidente por habilitar el debate sobre el aborto. Clarín. Obtenido de https://www.clarin. $\mathrm{com} /$ politica/dura-critica-monsenor-hector-aguer-presidente-habilitar-debateaborto_0_B1BdGsnOG.html.

Magnasco, R. (13 de agosto de 2020). La lucha contra el aborto no termina. La Nación. Obtenido de https://www.lanacion.com.ar/opinion/ la-lucha-aborto-no-termina-nid2420442.

Matthes, J. (2012). Framing Politics: An Integrative Approach. American Behavioral Scientist, 56(3), 247-259.

Menem, Z. (9 de agosto de 2020). La vida como derecho. Infobae. Obtenido de https:// www.infobae.com/opinion/2020/08/09/la-vida-como-derecho/.

Meyer, D. S. y Staggenborg, S. (1996). Movements, countermovements, and the structure of political opportunity. American journal of sociology, 101(6), 1628-1660.

Meyer, D. S. y Staggenborg, S. (2015). Opposing movement strategies in U.S. abortion politics. En Patrick, C. Research in Social Movements, Conflicts and Change (pp. 207-238). Ohio: Emerald Group Publishing.

Millett, K. (1975). Política sexual. México: Aguilar.

Ministerio de Salud. (2020). Aislamiento social, preventivo y obligatorio. Buenos Aires, Argentina. Obtenido de https://www.argentina.gob.ar/coronavirus/aislamiento.

Morán Faúndes, J. M. (2013). ¿Pro-Vida? ¿Cuál vida? Hacia una descripción crítica del concepto de "vida" defendido por la jerarquía católica. En Zurbriggen, R. y Anzorena, C. (comp.). El aborto como derecho de las mujeres. Otra historia es posible (pp. 39-59). Buenos Aires: Herramienta.

Mujeresdela Matria Latinoamericana.[Mumalá].(31 dejuliode2020).Registro Nacional de Femicidios. Observatorio MuMaLá "Mujeres, Disidencias, Derechos". Desde el 1ro de Enero al 31 de Julio del 2020. [Publicación de estado]. Facebook. Obtenido de https://www.facebook.com/MuMaLaNacional/posts/650623302479395.

ONU Mujeres. (8 de marzo de 2020). Declaración con motivo del Día Internacional de la Mujer a cargo de Phumzile Mlambo-Ngcuka, Directora Ejecutiva de ONU Mujeres. Obtenido de https://www.unwomen.org/es/news/stories/2020/2/ statement-ed-phumzile-international-womens-day. 
Austral Comunicación

Volumen 9, número 2 (Diciembre de 2020):519-551. ISSN 2313-9129

Organización Panamericana de la Salud. (2020). Enfermedad por el Coronavirus (COVID-19). Obtenido de https://www.paho.org/es/tag/ enfermedad-por-coronavirus-covid-19.

Perciavalle, A. (7 de agosto de 2020). Aborto legal: alertan que las pastillas de misoprostol cuestan más de 5.000 pesos y son inaccesibles para la mayoría. Clarín. Obtenido de https://www.clarin.com/sociedad/aborto-legal-alertan-pastillas-misoprostolcuestan-5-000-pesos-inaccesibles-mayoria_0_rfff1WSET.html.

Pereyra, S. (2010). Critique de la politique, expertise et transparence: la corruption en tant que problème public en Argentine (1989-2001) (Disertación doctoral). París: EHESS.

Pinedo, F. (9 de marzo de 2018). Una persona siempre está inacabada. La Nación. Obtenido de https://www.lanacion.com.ar/opinion/ una-persona-siempre-esta-inacabada-nid2115369/.

Portolés, A. (2005). Debates sobre el género. En Amorós, C. y De Miguel, A. Teoría feminista: de la ilustración a la globalización (Vol.3, pp. 13-60). España: Minerva ediciones.

Pride, R. A. (1995). How Activists and Media Frame Social Problems: Critical Events Versus Performance Trends for Schools. Political Communication, 12(1), 5-26.

Registro Nacional de Femicidios de la Justicia Argentina. (2019). Datos Estadísticos del Poder Judicial, 2019. Obtenido de https://www.csjn.gov.ar/omrecopilacion/docs/ informefemicidios2019.pdf.

Rich, A. (1986 [1976]). Of Woman Born. Motherhood as Experience and Institution. Nueva York: WW Norton.

Rodríguez Agüero, E. (2015). Intervenir desde los márgenes: Mujeres y feminismos en la revista Crisis. Argentina 1973-1976. NOMADíAS, (19), 105-128.

Roffo, J. (6 de marzo de 2018). Con 71 firmas que lo avalan, presentaron en Diputados un proyecto de despenalización del aborto. Clarín. Obtenido de https://www. clarin.com/politica/71-firmas-avalan-presentaron-diputados-proyectodespenalizacion-aborto_0_rymXcX2_z.html.

Rosales, M. B. (2018). Ciberactivismo: praxis feminista y visibilidad política en \#NiUnaMenos. Pléyade, (22), 63-85.

Rosolato, G. (1974). Ensayos sobre lo simbólico. Barcelona: Anagrama.

Rubin, S. (10 de marzo de 2018). La estrategia de la Iglesia contra el aborto: mensajes moderados y presión sobre el Congreso. Clarín. Obtenido de https://www. clarin.com/politica/estrategia-iglesia-aborto-mensajes-moderados-presioncongreso_0_rliX53Ztf.html.

Saccomano, C. (2017). El feminicidio en América Latina: ¿vacío legal o déficit del Estado de derecho? CIDOB, (117), 51-78.

Sádaba, T. (2008). Framing: el encuadre de las noticias: el binomio terrorismo-medios. Buenos Aires: La Crujía. 
Paola Ingrassia

La constitución de la violencia de género como problema público y los frames sobre aborto: revisión crítica de antecedentes y propuesta de análisis

Sagot, M. (2008). Estrategias para enfrentar la violencia contra las mujeres: reflexiones feministas desde América Latina. Athenea Digital. Revista de pensamiento $e$ investigación social, (14), 215-228.

Snow, D. A. y Benford, R. D. (1988). Ideology, frame resonance, and participant mobilization. International social movement research, 1(1), 197-217.

Snow, D. A. y Benford, R. D. (1992). Master frames and cycles of protest. En Morris, A. D. y Mueller, C. M. (eds.). Frontiers in social movement theory (pp. 133-155). New Haven: Yale University Press.

Staggenborg, S. (1991). The pro-choice movement: Organization and activism in the abortion conflict. Nueva York: Oxford University Press.

Staggenborg, S. (1993). Critical Events and the Mobilization of the Pro-Choice Movement. Research in Political Sociology, 6, 319-345.

Staggenborg, S. (2001). Beyond culture versus politics: A case study of a local women's movement. Gender \& Society, 15(4), 507-530.

Tarrow, S. G. (1994). Power in Movement: Social Movements, Collective Action, and Mass Politics in the Modern State. Estados Unidos: Cambridge University Press.

Tesei, P. (6 de marzo de 2018). Qué plantea el proyecto para despenalizar el aborto que se presentó en el Congreso. Infobae. Obtenido de https://www.infobae.com/ politica/2018/03/06/que-plantea-el-proyecto-para-despenalizar-el-aborto-quese-presento-en-el-congreso/.

Thomas, W. I. (2005). La definición de la situación. CIC. Cuadernos de Información y Comunicación, (10), 27-32.

Tilly, C. (1984). Social Movements and National Politics. En Bright, C. y Harding, S. (eds). Statemaking and Social Movements (pp.297-317). Estados Unidos: University of Michigan Press.

Torrado, S. (2003). Historia de la familia en la Argentina moderna (1870-2000). Buenos Aires: De la Flor.

Ulloa Ziáurriz, T. (2011). La prostitución: una de las expresiones más arcaicas y violentas del patriarcado contra las mujeres. En Lagarde, M. y Valcárcel, A. (coords.). Feminismo, género e igualdad (pp. 293-312). Madrid: Agencia Española de Cooperación Internacional al Desarrollo.

Universidad de San Andrés. (julio de 2020). PRENSA ESCRITA: A medida que aumenta la edad se incrementa el consumo de Clarín, La Nación e Infobae. En Especial medios de comunicación. Encuesta de Satisfacción Política y Opinión Pública. Obtenido de https://www.udesa.edu.ar/sites/default/files/especial_medios_espop_2020_meso. pdf.

Valcárcel, A. (2001). La memoria colectiva y los retos del feminismo. Santiago de Chile: CEPAL. 
Austral Comunicación

Volumen 9, número 2 (Diciembre de 2020):519-551. ISSN 2313-9129

Varela, N. (2008). Feminismo para principiantes. Barcelona: Ediciones B.

Veneranda, M. (7 de marzo de 2018). Los intelectuales vinculados al Gobierno se pronunciaron en favor de despenalizar el aborto. La Nación. Obtenido de https://www.lanacion.com.ar/politica/86-socios-del-club-politico-argentino-sepronunciaron-en-favor-de-despenalizar-el-aborto-nid2114801/.

Wollstonecraft, M. (1998). Vindicación de los derechos de la mujer. Asparkía: investigació feminista, (9), 181-186. Obtenido de https://www.raco.cat/index.php/ Asparkia/article/view/108391/154822.

\section{Legislación citada}

Ley 26485 de Protección Integral a las Mujeres, BO 11/03/2009. Obtenido de http:// servicios.infoleg.gob.ar/infolegInternet/anexos/150000-154999/152155/norma. htm.

Ley 26522 de Servicios de Comunicación Audiovisual, BO 10/10/2009. Obtenido de http://servicios.infoleg.gob.ar/infolegInternet/anexos/155000-159999/158649/ norma.htm.

Ley 26791 de Modificación del Código Penal, BO 14/11/2012. Obtenido de http:// servicios.infoleg.gob.ar/infolegInternet/anexos/205000-209999/206018/norma. htm.

Ley 27499 Ley Micaela de capacitación obligatoria en género para todas las personas que integran los tres poderes del estado, BO 19/12/2018. Obtenido de http:// servicios.infoleg.gob.ar/infolegInternet/anexos/315000-319999/318666/norma. htm. 